
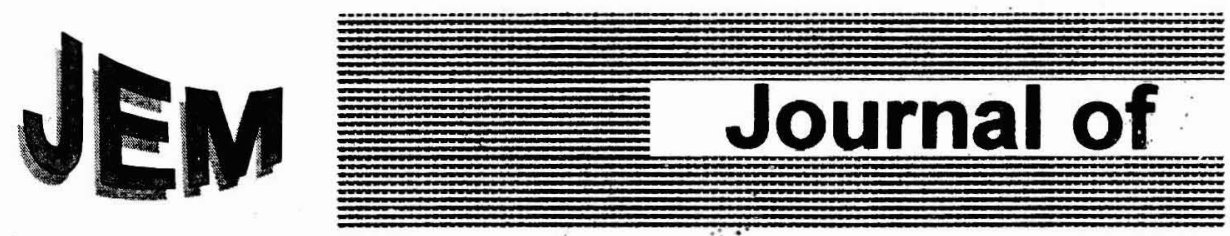

\title{
EDUCATIONAL MANAGEMENT
}

A Bi-annual Publication of

THE INSTITUTE FOR EDUCATIONAL PLANNING AND ADMINISTRATION

(IEPA)

University of Cape Coast, Ghana. 


\section{EMPLOYING MANAGEMENT BY OBJECTIVES IN MULTI-CAMPUS ADMINISTRATION OF A TERTIARY INSTITUTION, HOW FEASIBLE ?}

\section{Christie Okae-Anti}

Educational managers in tertiary institutions operate basically in four areas: to maximise results, by harmonising immediate and longrange goals; to establish precise goals and measurable objectives; and to evaluate progress toward pre-determined goals and objectives, to organise, motivate, communicate and strengthen superordinates, peers and subordinates (Hostrop, 1983). In order to achieve results in these areas it is assumed that the educational manager will adopt modern management techniques since academic institutions, though solely for teaching and research, still have some resemblance of corporate bodies. The institution may acquire property and let out facilities for its own good and for the well being of the community (community service). On the other hand some schools of thought are not in favour of employing modern management techniques like Programme Evaluation and Review Technique (PERT) or Management by Objectives (MBO) in university administration. Any innovative manager, however, would like to try to incorporate one of these techniques in the management of academic institutions because they are corporate bodies in their own right.

Thus an academic institution whose management employs modern management techniques is not far from enhancing the efficiency and effectiveness of the institution.

\section{Modern Management Techniques-Management by Objectives (MBO)}

Management by Objectives essentially means that the organisation determines exactly what it intends to accomplish, and allocates to every department or division what it must contribute so that its objectives may be met. By this system, every manager knows what the objective is for the entire organisation and what his own department must accomplish.

Without $\mathrm{MBO}$ an institution or a corporation could have a very strong desire to grow, but the approach might be haphazard. With $\mathrm{MBO}$, the institution might 
establish goals of short, intermediate or long-range duration. This would then require specific objectives for the various divisions or departments. Each division would have specific things to do in order for the university to attain the desired objectives. The specific numerical goals of each division should be easily measurable. In establishing objectives it should be possible to set a numerical base point from which progress can be measured and this is what MBO does better. MBO concentrates the organisation's efforts on opportunities rather than problems, and this can be of great help to a public relations programme of any institution.

Although Adamolekum (1989) asserted that MBO could not possibly be imported into the functions of most of the staff of the Registrar's department, an attempt at using MBO would be of immense benefit if the Registrar is very innovative. Assuming that the measure of a manager's performance is the magnitude of his contribution to the achievement of central administrative goals, MBO agreement may complement and reinforce the attainment of the total organisational goals set by the central administration.

In employing $\mathrm{MBO}$ the registrar and others in his department would define the major areas of their responsibilities and establish measures for operation. For instance, in the major areas of the Registrar's department Academic, Personnel and General Administration - routine, creative and problem-solving objectives may be initiated as part of the MBO plan. The department may then establish a goal, either short-term or intermediate. (See Table 1).

Table 1 Measure of Performance of the major areas of the Registrar's Department

\begin{tabular}{lcc}
\hline Major Areas & Routine Objective & $\begin{array}{c}\text { Measure of Satisfactory } \\
\text { Performance }\end{array}$ \\
\hline General Administration & Plant maintenance & $\begin{array}{c}\text { Complement of quality } \\
\text { of plant cleanliness \& } \\
\text { maintenance }\end{array}$
\end{tabular}

Academic Affairs Collate results from Timely publication of divisions results

Personnel Personnel appraisal Staff development

(Staff needs met) 
The deputy registrar in charge of a major area could also define the specific responsibility of his own position and discuss this with the registrar until mutual agreement is reached and committed into writing. The divisions, departments, units and sections could also define common objectives, which should be consistent with the goals of the organisation. These objectives become measures of the superordinates' responsibility, hence they are committed to assist for total results and success.

The registrar's department which is the hub of administration could set problem solving objectives. If such objectives are made, probable innovations in the administrative process may be enhanced. For instance, a more effective means of participatory democracy in university governance could be developed while at the same time obtaining agreements as to who is accountable for what.

MBO could also be initiated in the human resource development sector of a university. The Deputy Registrar in charge of staff training and development could set objectives for various staff needs in the university and run workshops along these lines. This way both career and personal development needs may be attained which could consistently promote the goals of the organisation. It is to be noted that career and personal or individual developments are inter-twined and very crucial in the development of an organisation.

Even though the above examples are in the Registrar's Department, it should not be taken to mean that the academic divisions or units cannot initiate plans using MBO. Adamelokun (1989) puts it that all the functions of $\mathrm{MBO}$ are present in the university teaching process without the Senate or any officials thinking about MBO. If university teaching process is more resultoriented then the challenge is widely thrown to a multi-campus establishment to embrace MBO.

Lessons to be drawn from MBO for a multi-campus establishment

- Each satellite campus must identify its goals and objectives.

- Each should define managerial responsibility in terms of expected results.

- Each should measure performance and achieve- 
ment against those goals and objectives.

- Each must work within a certain time frame.

- The achievement and performance of each satellite campus should be the total result and success of the common goal for the university.

Thus the three satellite campuses of the University College of Education, Winneba, operating under a common mission may visibly embrace the principle of $\mathrm{MBO}$, for after all, the large number of disciplines and the interrelationship through the division system put the university in a better position to assemble the necessary skills and expertise to attain the mission and visions of a young multi-campus university.

\section{References}

Adamelokum, N. K. (1989). Selected topics in university administration. Macmillan: Nigeria.

Hostrop, R. W. (1983). Managing education for results. Palm Springs, California: ETC Publications. 


\section{NOTES FOR CONTRIBUTORS}

Journal of Educational Management seeks scholarly papers in:

i. Theoretical expositions,

ii. Critical analysis of educational management policies,

iii. Reports on empirical research in educational management,

iv. Innovative ideas about educational policy formulation and implementation,

v. Studies of comparative educational management system,

vi. Reports of practical application of educational management models,

vii. Review of research and practice in educational management models.

JEM is published two times in the year, in May and November.

\section{Editorial Procedure}

Manuscripts will be accepted from practising educational managers, planners, administrators, researchers and teachers in Ghana and overseas. Relevant papers on related experiences from authorities in corporate business are also welcome. Each paper submitted will first be checked whether or not it falls within the scope of, and conforms to, the stylistic requirements of the Journal. A manuscript that does not satisfy the requirements will not be sent for review. A report on the article and a copy of the journal's guidelines will be sent to the author. The manuscript may then be re-submitted after necessary corrections have been made.

All manuscripts that are acceptable will be subjected to anonymous peer evaluation, usually by at least two members of the Editorial Board. If the article is found publishable but requires specified changes the editor will ask the author to make the changes and re-submit. After acceptance an article may not be published anywhere without written approval from the Editor.

Technical and Stylistic Requirements

1. Manuscripts which should be 10 to 20 pages in length should be submitted in triplicate, typed double-space on one side only of A4 paper. Contributors are requested to submit a copy of their 
manuscript on a 3.5 high density computer disk, with file stored in a word processing format (Microsoft Word 6.0). Report of original research should consist of distinct sections and should appear in the sequence of these stages: introduction, method, result, discussion.

2. Articles should be accompanied with an Abstract of not more that 150 words in length, typed on a separate sheet. Brief Reports/ Comment need no abstract.

3. To ensure anonymity in the reviewing process the body of the paper should bear only the title of the paper on the front page as a means of identification. Authors are to attach to each manuscript a cover page giving the tile, authors' names, professional status and/or responsibility post, institutional affiliation and addresses.

4. Tables diagrams, graphs and figures should be in the appropriate places in the body of the paper.

5. Authors should adhere strictly to the style in the fourth edition of the publication Manual of the American Psychological Association (APA).

6. The list of cited references for Articles should appear at the end of the paper. They should include the author's name, year of publication in brackets, title of publication, the volume and or page number (s), the place of publication and the publisher.

7. Explanatory footnotes should be used sparingly. They are to be indicated in the text by superscripted numbers preceding the reference page. At the end of the paper the footnotes should be listed in sequence.

8. Manuscript submission, including all subsequent editorial correspondence(s) should be addressed to:

Prof. S. O. Owolabi, (Editor)

Journal of Educational Management

Institute for Educational Planning and Administration

University of Cape Coast

Cape Coast, Ghana. 